\title{
ASPECTOS JURÍDICOS DA EXPOSIÇÃO DE DADOS PESSOAIS NA INTERNET E A SUA RELAÇÃO COM O DIREITO FUNDAMENTAL À PRIVACIDADE
}

\author{
Walyf Lopes da Silva ${ }^{1}$ \\ Camila Medeiros da Silva ${ }^{2}$ \\ Carollayne Reges Mateus ${ }^{3}$ \\ Greicy Kelle Sousa Rocha ${ }^{4}$ \\ Larice Inez Alves Cruvinel ${ }^{5}$ \\ Maria Fernanda Rodrigues da Silva ${ }^{6}$
}

RESUMO: O presente artigo tem como objetivo promover uma reflexão e traçar um panorama geral acerca da crescente exposição de dados na internet em uma sociedade que é cada vez mais conectada às novas tecnologias de informações e entender como isso pode violar o direito à privacidade - garantia fundamental prevista na norma de maior importância do ordenamento jurídico brasileiro. Inicia-se o artigo fazendo uma contextualização histórica e sociopolítica de como ocorreu o surgimento da lei que, atualmente, regula a respeito da proteção da privacidade na internet - Lei geral de Proteção de Dados (LGPD). Além disso, é tratado acerca de como está postulado na lei supramencionada a proteção do direito a privacidade e quais são as sançoes caso haja a violação. Fora abordado, também, a respeito da privacidade e a intimidade na internet e o que essas palavras significam para determinados pensadores. Por fim, foi exposto um caso concrento envolvendo a violação do direito a privacidade e a intimidade na internet em determinada rede social. Nesse sentido, a pesquisa foi realizada pelo método qualitativo, mediante revisão bibliográfica. Ressalta-se, ainda, a utilização do método denominado de hipotético-dedutivo.

Palavras-chave: Exposição de Dados. Direito à Privacidade. Internet. Sanções. Violação.

ABSTRACT: This article aims to promote a reflection and outline an overview of the increasing exposure of data on the internet in a society that is increasingly connected to new information technologies and understand how this can violate the right to privacy guarantee fundamental provided for in the most important norm of the Brazilian legal system. The article begins with a historical and socio-political contextualization of how

\footnotetext{
I Acadêmico da Faculdade de Ensino Superior da Amazônia Reunida Fesar/Afya. Graduando em Direito Faculdade Fesar do Pará. E-mails: walyflopes@gmail.com.

${ }^{2}$ Acadêmica da Fuldade de Ensino Superior da Amazônia Reunida Fesar/Afya. Graduanda em Direito Faculdade Fesar do Pará. camilamedeirosi407@gmail.com

${ }^{3}$ Acadêmica da Faculdade de Ensino Superior da Amazônia Reunida Fesar/Afya. Graduanda em Direito Faculdade Fesar do Pará. carollaynemateus@gmail.com.

${ }^{4}$ Acadêmica da Faculdade de Ensino Superior da Amazônia Reunida Fesar/Afya. Graduanda em Direito Faculdade Fesar do Pará. greicyk36o@gmail.com

${ }^{5}$ Acadêmica da Faculdade de Ensino Superior da Amazônia Reunida Fesar/Afya. Graduanda em Direito Faculdade Fesar do Pará. laricealvesdraxler@gmail.com

${ }^{6}$ Acadêmica da Faculdade de Ensino Superior da Amazônia Reunida Fesar/Afya. Graduanda em Direito Faculdade Fesar do Pará. mariaferdsi352@gmail.com
} 
the law that currently regulates the protection of privacy on the internet - General Data Protection Law (LGPD) emerged. In addition, it deals with how the protection of the right to privacy is postulated in the aforementioned law and what are the sanctions in case of violation. It was also addressed about privacy and intimacy on the internet and what these words mean to certain thinkers. Finally, a concrete case involving the violation of the right to privacy and intimacy on the internet in a certain social network was exposed. In this sense, the research was carried out using the qualitative method, through a literature review. The use of the so-called hypothetical-deductive method is also noteworthy.

Keywords: Data Exposure. Right to Privacy. Internet. Sanctions. Violation.

\section{INTRODUÇÃO}

A internet tornou-se um mecanismo indispensável ao pleno funcionamento da sociedade contemporânea, visto que é o principal meio de disseminação de informações e de comunicação entre os indivíduos que a compõem. Sendo assim, está presente nas mais variadas esferas sociais e mais diversas localidades, o que possibilitou a expansão de sua zona de influência em todos os locais do mundo ${ }^{7}$, inclusive no Brasil. Nesse último, - da mesma forma que na maioria dos outros Estados - com o advento da pandemia, em que diversas tarefas passaram a ser realizadas mediante o uso de instrumentos virtuais com escopo de evitar a propagação do vírus Covid-ı, esse processo de expansão tecnológico se intensificou em proporções inéditas em todo o país .

Nesse contexto, destaca-se que o desenvolvimento de novas tecnologias de informações modificou as relações humanas, seja em escala macro ou micro, transformando a forma como cada indivíduo interage com o outro nas plataformas digitais. E um dos maiores produtos desse progresso tecnológico, sem sombra de dúvidas, foi o surgimento das redes sociais, as quais são amplamente utilizadas pela sociedade ${ }^{9}$. Tais redes de interações sociais virtuais, em consonância a RECUERO (2009), podem ser definidas como "um grupo de pessoas que estão em relação por intermédio do ciberespaço, denotando um alto grau de intimidade pessoal, coerção social e continuidade no tempo". Desse modo, as redes sociais propiciam a interação social mediante exposição de suas vidas e opiniões, nas quais qualquer indivíduo com acesso à Internet é potencialmente um emissor e receptor de conteúdo informacional (FUGAZZA; SALDANHA, 2017).

\footnotetext{
${ }^{7}$ Em janeiro de 2021, o número de pessoas que utilizam a internet no mundo atingiu 4,66 bilhões de pessoas, um aumento de 316 milhões (7,3\%) em relação ao mesmo período do ano anterior. Ou seja, esse número corresponde a $59,5 \%$ do total da população mundial, logo, sua taxa de penetração social possui número elevado. (Global Digital Overview 2021. We Are Social e HootSuite, 2021, p.8).

${ }^{8}$ O Centro Regional de Estudos para o Desenvolvimento da Sociedade da Informação (Cetic.br), departamento do Núcleo de Informação e Coordenação do Ponto BR (NIC.br), divulgou, em 2020, dados que comprovam o crescimento do acesso a internet durante o período da pandemia no Brasil, visto que o levantamento aponta que tal levantamento feito em 2019 indicava que $74 \%$ da população brasileira usavam esse meio tecnológico, entretanto, no início da pandemia o NIC.br registrou umpico de cerca de 13,5 terabits por segundo - dado que comprova que o tráfego na rede atingiu quantidade inédita no país. Ademais, com os dados expostos por essa pesquisa torna-se evidente que a proporção de usuários aumentou nas classes ABCDE.

${ }^{9}$ Até a data da pesquisa a população total mundial era de 7,83 bilhões de pessoas, das quais 4,20 bilhões eram usuários de mídias sociais, volume que corresponde a $53.3 \%$ da população total. (Global Digital Overview 202r. We Are Social e HootSuite, 202I, p.8).
} 
Verifica-se que toda essa possibilidade de interação, no entanto, não apresenta somente pontos positivos, pois esses ambientes virtuais também servem de palco para a insegurança e cometimento de uma grande quantidade de violações a certos direitos fundamentais relacionados a vida privada e a liberdade individual (LIMA, 20I6, p.87).

Tendo em vista o atual cenário, percebe-se que tal assunto - a violação dos direitos a privacidade e a liberdade na internet - é objeto de grandes discursões no direito brasileiro, uma vez que tal tema trata-se do desrespeito de garantias fundamentais postuladas pela Constituição Federal de 1988, bem como dos limites a serem impostos no âmbito das redes sociais. Com isso, fica em evidência toda a dificuldade em definir e reger as múltiplas formas de interações desse ambiente digital, que, por fazer parte da sociedade e exercer demasiada influência sobre esta, precisa seguir parâmetros determinados pelo Direito para que possa ser mantida a ordem social e a segurança jurídica. Dessa maneira, a vivência virtual, assim como já ocorre com os demais mecanismos de relações humanas, precisa ser regulada pelo ordenamento jurídico. No entanto, em razão de ser um fenômeno relativamente recente, as redes sociais carecem dessa previsão legal e jurídica.

Perante a essa relevância adquirida pela internet e da complexidade das relações provenientes desse ambiente, gradativamente, o Direito brasileiro tem visado alcançar esse setor para proteger os direitos e deveres dos seus usuários (MORAES; TEFFÉ, 2017). Para tanto, leis foram criadas como a Lei $\mathrm{n}^{\mathrm{O}} 13.709$ de $\mathrm{I} 4$ de agosto de 2018 , mais conhecida como Lei Geral de Proteção de Dados (LGPD) e, também, a Lei n ${ }^{\circ} 2.965$ de 23 de abril de 2014, conhecida como Marco Civil da Internet ("MCI"), instituídas com a finalidade de dar mais segurança aos sujeitos que se utilizam da internet, mediante a proteção de dados pessoais, assim como certificar a preservação de certos direitos.

\section{OBJETIVO}

Diante do exposto, torna-se imprescindível indagar: a exposição de dados pessoais, sobretudo em redes sociais, viola o direito à privacidade previsto na Constituição Federal? A partir disso, o presente estudo tem como objetivo promover uma reflexão e traçar um panorama geral acerca da crescente exposição de dados na internet em uma sociedade que é cada vez mais conectada às novas tecnologias de informações e entender como isso pode violar o direito à privacidade - garantia fundamental prevista na norma de maior importância do ordenamento jurídico brasileiro. Além disso, pretende analisar a escassa legislação sobre o tema e verificar se esta é realmente capaz de regulamentar esse importante setor em crescimento.

\section{LGPD NA INTERNET: CONTEXTUALIZAÇÃO HISTÓRICA E SOCIOPOLÍTICA}

A Lei Geral de Proteção de Dados (LGPD), foi sancionada no Brasil em I4 de agosto de 2018, com a promulgação da Lei $n^{\circ}$ 13.709. A lei em questão é a norma brasileira que regulamenta o uso de dados de pessoas físicas pelas empresas, criando regras claras a respeito de como as organizações devem coletar, armazenar e compartilhar as informações dos usuários. Diante disso, como foi abordada tal norma não proíbe o registro ou armazenamento de dados, mas os relaciona com o direito do consumidor e as obrigações das empresas em proteger os dados de seus usuários. 
Nesse sentido, a lei supracitada visa promover a proteção de dados pessoais e impedir a circulação entre empresas e indivíduos. Dessa maneira, faz-se necessário citar um exemplo para melhor elucidar o que foi tratado. Imagine que um cliente informou os seus dados à empresa $\mathrm{X}$ e, no formulário, declarou que tinha interesse em receber e-mails promocionais da empresa, ou seja, o cliente consentiu fornecer as informações pessoais e, também, em ser comunicado sobre materiais de venda em promoção. Nessa circunstância, é de suma importância que nessa relação exista a proteção de dados, uma vez que o cliente disponibilizou informações cruciais a respeito da sua vida pessoal ao informar os seus dados a empresa.

Diante disso, é mister salientar que a LGPD teve pressupostos a sua criação. Nesse diapasão, no ano de 198I - tendo em vista o aumento da circulação transfronteiriça de dados pessoais por intermédio de processos automatizados - a proteção de dados tornou-se um objeto de atenção do Conselho Europeu, o que levou à primeira convenção internacional sobre o assunto - a Convenção de Proteção Pessoal ${ }^{10}$. Diante desse cenário, posteriormente, na União Europeia, foi criada a Diretiva 95/46/CE de 1995 a qual reforçou o direito à proteção de dados. Nesse viés, no seu preâmbulo, a diretiva fornece todos os fundamentos e objetivos para justificar a utilização da proteção de dados, esses que, na maioria dos casos, aplica-se à situação do Brasil e a qualquer país que cumpra os princípios contidos na Declaração Universal dos Direitos Humanos, a qual diz em seu art. I2 que ninguém será sujeito à interferência na sua vida privada, na sua família, no seu lar ou na sua correspondência, nem a ataque à sua honra e reputação (ORGANIZAÇÃO DAS NAÇÕES UNIDAS, 1948). Perante o exposto, percebe-se que o direito a proteção de dados já era previsto de forma genérica e implícita no artigo supramencionado. Dessa forma, todo ser humano tem direito à proteção contra interferências ou ataques a vida privada e aos seus dados pessoais, como bem preceitua a Diretiva 95/46/CE do Parlamento Europeu e do Conselho:

2. (...) os sistemas de tratamento de dados estão a serviço do Homem; que devem respeitar as liberdades e os direitos fundamentais das pessoas singulares independentemente da sua nacionalidade ou da sua residência, especialmente a vida privada, e contribuir para o progresso económico e social, o desenvolvimento do comércio e o bem-estar dos indivíduos; (EUROPEIA, UNIÃO [s. p])

Além disso, no ano de 2018, entrou em vigor a lei GDPR (General Data Protection Regulation), ou o Regulamento Geral sobre a Proteção de Dados, que passou a regulamentar o tratamento de dados de toda a União Europeia, influenciando, assim, outros países a criarem seu próprio estatuto.

No entanto, é importante salientar que a primeira discussão aberta no Brasil a respeito do assunto ocorreu no ano de $2010^{\mathrm{II}}$, tendo em vista que nesse ano surgiram os

\footnotetext{
ro A Convenção ro8 do Conselho da Europa das Pessoas Singulares no que diz respeito ao tratamento Automatizado de Dados Pessoais, de 28 de janeiro de 1981, foi o primeiro instrumento juridicamente vinculativo adotado no domínio da proteção de dados. Disponível em: https://www.gov.br/anpd/pt$\mathrm{br} /$ assuntos/noticias/anpd-participa-da-4ra-reuniao-plenaria-da-convencao-ıo8. Acessado: 15/10/2021.

${ }^{\text {II }} \mathrm{O}$ processo público e legislativo começou em 20ı0, após o Ministério público promover uma consulta pública a respeito da Proteção de Dados Pessoais, essa que resultou, posteriormente, na propositura do PL 5276/2016, anexado ao PL 4060/2012, perante a Câmera dos Deputados. Disponível em:
} 
primeiros casos públicos de vazamento de dados e em decorrência disso tornou-se mais frequente a quantidade de casos relacionado a tal problemática, como o episódio envolvendo vazamento de dados pessoais por consequência da invasão da rede PSN da Sony em $201 I^{12}$ e no mesmo ano ocorreu um dos casos mais famoso no Brasil, o que envolve a atriz brasileira Carolina Dieckmann, essa que teve suas fotos de cunho íntimo vazadas na internet após ter seu computador pessoal invadido por um Hacker ${ }^{13}$. Diante de tais acontecimentos, foram promulgadas a Lei de Acesso à Informação (Lei no $12.527 / 2011$ ) e a Lei Carolina Dieckmann (Lei no 12.737/2012).

É evidente que após a postulação das leis mencionadas, essas influenciaram a criação da lei intitulada como Marco Civil da Internet, tal normativa entrou em vigor no ano de $2014 \mathrm{e}$ foi uma das primeiras normas a dá ênfase ao direito à privacidade na internet. Diante desse contexto, é relevante argumentar que no ano seguinte foi feita a segunda consulta pública acerca do tema em analise e nessa a questão ganhou mais espaço, mais importância e consequentemente a ideia da criação de uma lei que tratasse especificadamente a respeito do assunto ${ }^{\mathrm{I} 4}$. Dessa forma, no ano de 2018 foi aprovada a Lei Geral de Proteção de Dados (LGPD), que estabelece regras sobre coleta, armazenamento, tratamento e compartilhamento de dados pessoais, impondo mais proteção e penalidades para o não cumprimento. Entretanto, verifica-se que a lei entrou em vigor apenas em setembro de 2020 e nem foi totalmente, uma vez que sofreu várias prorrogações - no que tange a vigência e punição - e por consequência disso somente após I de agosto de 202I que as sanções da LGPD puderam ser aplicadas efetivamente.

\section{PROTEÇÃO DA PRIVACIDADE NA LGPD}

No Brasil a privacidade possui patamar de direito fundamental, assegurado pela Constituição Federal em seu art. $5^{\circ}$, inciso X. No entanto, percebe-se que tal direito não vem sendo amplamente protegido, uma vez que o amparo a ele foi fragilizado pelas inovações tecnológicas. Isso porque, consoante Rodotá (2008) a privacidade não pode ser mais entendida como o "direito de permanecer só", abrangendo também novas dimensões em razão da evolução social. Assim, a privacidade também deve ser compreendida no contexto de coleta e tratamento de dados pessoais.

A violação a tal direito ocorre porque as informações pessoais se tornaram uma mercadoria de grande valor (Finkelstein e C. Finkelstein, 2019). Uma vez que para que o usuário entre nos sites ele deve fornecedor seus dados. Contudo, esses titulares dos dados

https://baptistaluz.com.br/institucional/lei-geral-de-protecao-de-dados-do-brasil-analise/. Acessado em: 15/10/2021.

${ }^{12} \mathrm{Um}$ ataque de Hacker entre os dias 16 e i7 de abril de $201 \mathrm{I}$ obrigaram a Sony a desligar os servidores da rede de games on-line do PlayStation 3 e do PSP. Disponível em: http://gi.globo.com/tecnologia/noticia/20II/o5/entenda-o-ataque-rede-line-do-playstation-3-psn.html.

Acessado em: 15/10/2021.

${ }^{13}$ Substantivo masculino e feminino. Além disso, significa: quem invade sistemas computacionais ou computadores para acessar informações confidenciais ou não autorizadas, apontando possíveis falhas nesses sistemas. Disponível: https://www.dicio.com.br/hacker/. Acessado em: 15/10/202I.

${ }^{14}$ No dia 28 de janeiro de 2015 o Ministério Público lançou, pela segunda vez, a consulta pública para discutir a proteção de dados pessoais armazenados em centrais dentro ou fora do País. Disponível em: https://www.camara.leg.br/noticias/449278-consulta-publica-sera-base-para-projeto-de-lei-sobre-protecaode-dados-pessoais/. Acessado em: 15/10/2021. 
não sabem qual o tratamento dado a eles. Com isso, é imprescindível destacar que os dados pessoais possuem enorme valor para as empresas, pois estas utilizam ferramentas como o big data ${ }^{15}$ para coleta verificação de um padrão de comportamento dos usuários, com o intuito de mostrar-lhes o que mais os agrade. Nesse viés, essa é a forma mais branda de violação praticada pelas empresas. Dessa maneira, uma forma mais grave se caracteriza quando há o compartilhamento indevido de tais dados, isto é, sem o devido consentimento do titular.

Em vista disso, faz-se conveniente mencionar um exemplo marcante acerca da exposição de dados. Este refere-se às eleições americanas de 20ı6, onde à empresa britânica Cambridge Analytica, ${ }^{16}$ realizou o tratamento de dados mediante plataformas digitais como Google, Snapchat, Twitter, Facebook e YouTube, para direcionar mensagens, bem como anúncios em prol da campanha do então candidato Donald Trump na finalidade para manipular a opinião pública, portanto, romperam os termos de uso da plataforma.

Diante disso, com escopo de abranger todas as esferas sociais a fim de manter a ordem social e assegurar os direitos mínimos o Direito evolui. Assim, foram criadas leis para mitigar a violação dos dados pessoais e assegurar a privacidade no ambiente digital. A primeira a tratar do tema foi o Marco Civil da Internet (Lei $n^{\circ}$ 12.965/14). Logo em seguida, foi promulgada a Lei Geral de Proteção de Dados (Lei n 13. 609/18), que somente entrou em vigor em 2020. Desse modo, seu art. $2^{\circ}$ impõe o respeito á privacidade, bem como em seu art.i7:

Art. 17. Toda pessoa natural tem assegurada a titularidade de seus dados pessoais e garantidos os direitos fundamentais de liberdade, de intimidade e de privacidade, nos termos desta Lei.

Art. 2o- A disciplina da proteção de dados pessoais tem como fundamentos: I - o respeito à privacidade;

Dessa forma, a transgressão a tais direitos poderá desencadear a reclamação dos usuários frente ao encarregado, bem como poderá se valer do art. 4I, $\S^{2}{ }^{\circ}$ da LGPD. Assim, torna-se uma grande evolução para a proteção à privacidade. Embora existam aspectos que devem ser melhorados.

\section{IMPACTOS DA LGPD NAS EMPRESAS}

Como visto, as empresas beneficiam-se demasiadamente dos dados fornecidos. Em razão da entrada em vigor da LGPD a sua utilização desses dados foi limitada. No entanto, o objetivo da supramencionada lei não foi prejudicar as empresas, mas assegurar ordem na Sociedade Informática.

Nesse diapasão, foi dado um largo prazo ( 2 anos) para que estas se adequassem a nova legislação. Entretanto, conforme Feitosa $(2021)^{17}$ poucas foram as empresas que preencheram corretamente os requisitos da LGPD para a coleta e tratamento de dados pessoais.

\footnotetext{
${ }^{\text {Is }}$ É uma ferramenta utilizada pelas empresas para análise e estudo dos dados fornecidos pelas empresas para que seja criado um padrão de comportamento dos usuários.

${ }^{16}$ Contém informação detalhada no JORNAL THE GUARDIAN, dado que teve acesso a um documento interno da empresa que comprova quais estratégias utilizadas para direcionar os votos dos norte-americanos.

${ }^{17} \mathrm{O}$ impacto da LGPD nas empresas 2021. (Migalhas, 2021. Disponível em:

〈https://www.migalhas.com.br/depeso/34043I/o-impacto-da-lgpd-nas-empresas-em-2021〉).
} 
Para o especialista Fábio Pereira ${ }^{\mathrm{I} 8}$, os principais impactos são a necessidade de um $\mathrm{DPO}^{19}$; a obrigatoriedade de relatórios com o escopo de comprovar que há a proteção de dados por parte da empresa; obrigatoriedade ágil ás solicitações dos titulares ${ }^{20}$; gera os canais de contato, ou seja, deve disponibilizar contatos da empresa para que se torne mais viável a busca dos direitos pelos titulares; foi criada a ANPD para a fiscalização das empresas; e as empresas devem avisar aos titulares quando os dados destes deixam o Brasil.

Ademais, foi estabelecido que as empresas coletem apenas os dados essenciais (FEITOSA, 202I).

Quanto a vulnerabilidade dos consumidores perante as empresas, mormente no meio digital. Convém destacar que muitas vezes os consumidores estão expostos a coleta de dados indevida por falta de conhecimento. Exemplo disso, é a amplamente conhecida opção "Li e Aceito os Termos", ${ }^{21}$ ou seja, leu e concorda com todas as anuências as quais estão sujeitos em determinada relação de consumo. Diante desse histórico mencionado, surge à indagação não somente sobre a privacidade abusiva, como também sobre os riscos éticos e de controle social. Nota-se que um dos mais importantes eixos da economia baseia-se na total vigilância aos dados dos consumidores, no que tange esses dados na informação de capital, dessa forma fragilizando a privacidade do sujeito.

\section{FOLHA DE PAGAMENTO}

A folha de pagamento envolve uma vasta variedade de fatores, o setor responsável é o Departamento Pessoal (DP), ${ }^{22}$ pois tem acesso diário a dados pessoais e até mesmo sensíveis de empregados, empresas, clientes e fornecedores.

Desse modo, deve ser observada a proteção de dados na gestão da folha de pagamentos, visto que envolve não apenas dados pessoais, mas também informações sensíveis de cada colaborador. Por conseguinte, é exigido atenção dos gestores, para certificarem de que seus fornecedores cumprem os requisitos legais de privacidade.

Nesse sentido, esses dados são extremamente necessários para o cumprimento de obrigações legais. Com o advento da LGPD todos esses dados deverão ser protegidos seguindo as suas diretrizes. Por isso, todos os indivíduos que tiveram seus dados armazenados terão direito de saber como, quando e onde esses serão operados. Em vista disso, na folha de pagamento são utilizados somente dados obrigatórios por lei, como o

\footnotetext{
${ }^{18}$ Sócio da Veirano Advogados. Possui foco na área de tecnologia da informação, na qual obteve diversos reconhecimentos.

LGPD: especialista lista 7 impactos para empresas e usuários. (Canaltech, 2020. Disponível em: $<$ https://canaltech.com.br/seguranca/lgpd-especialista-lista-os-7-impactos-para-empresas-e-usuarios-I $70915 />$.).

I9 Uma pessoa destinada a tratar de temas envolvendo tratamento de dados pessoais, superviconando seu tratamento. Ademais, compete a este também lidar com as requisições dos titulares e da ANPD Autoridade Nacional de Proteção de Dados Pessoais.

${ }^{20} \mathrm{O}$ prazo é de is dias

${ }^{21}$ Exposto exemplificação do termo "Li e aceito os termos: violações a direitos fundamentais nos termos de uso das plataformas digitais. Retirado da revista: Internet \& Sociedade, V.I, N.I - 2020, I semestre.

${ }^{22}$ DP: Departamento Pessoal é o setor técnico responsável pela administração dos funcionários, bem como sua folha de pagamento.
} 
Fundo de Garantia do Tempo de Serviço (FGTS) ${ }^{23}$ e o Instituto Nacional de Seguro Social (INSS) ${ }^{24}$. Portanto, somente são coletados dados indispensáveis para o seu devido tratamento, por profissionais do Departamento Pessoal que deverão seguir todos os princípios da LGPD armazenando-os de forma minuciosa, afim de garantir segurança. Com isso, evitar futuros incidentes negativos, uma vez que todos esses dados são sigilosos, uma vez que envolvem dados sensíveis.

\section{SANÇÕES APLICÁVEIS}

As sanções contidas na LGPD podem ser entendidas como medidas coercitivas indiretas, com o intuito de inibir a violação das obrigações previstas na referida lei. Nesse sentido, é certo que a aplicação das sanções não ocorre somente em consequência ao vazamento de dados.

Insta observar que suas sanções começaram a ser aplicadas a partir de agosto de 2021. Tais, medidas corretivas estão presentes na Seção I, presente no Título VIII, o qual trata da fiscalização. Nela, observa-se que as sanções são administrativas, em sua maioria, mas também existem sanções penais e civis.

Ademais, é notável uma gradação em sua aplicação (GARCIA, 2020), em que se ordenam da seguinte forma, respectivamente: advertência, multa simples, multa diária, bloqueio de dados, eliminação de dados, suspensão do funcionamento do banco de dados, suspensão do exercício do tratamento de dados, proibição parcial ou total do exercício de atividades que se relacionem com o tratamento de dados. Além disso, é possível também haver a publicidade da infração.

Apesar de existir esse sistema de gradação, é exequível que sejam aplicadas de forma isolada, ou cumulativamente, desde que da interpretação do caso concreto resulte nessa conclusão, bem como em todos os casos respeitando o princípio da proporcionalidade. No entanto, para que isso ocorra devem ser considerados critérios objetivos e subjetivos previstos no $\S^{\circ}$, do art. 52, quais sejam:

\footnotetext{
I - a gravidade e a natureza das infrações e dos direitos pessoais afetados; II- a boa-fé do infrator; III - a vantagem auferida ou pretendida pelo infrator; IV - a condição econômica do infrator; V - a reincidência; VI - o grau do dano; VII - a cooperação do infrator; VIII - a adoção reiterada e demonstrada de mecanismos e procedimentos internos capazes de minimizar o dano, voltados ao tratamento seguro e adequado de dados, em consonância com o disposto no inciso II do $\S 2^{\underline{O}}$ do art. 48 desta Lei;
}

Imprescindível destacar que as sanções devem ser aplicadas somente após um adequado rito processual, em que será assegurado contraditório e ampla defesa. Por fim, indispensável destacar que a fiscalização das empresas, organizações, e instituições

\footnotetext{
${ }^{23}$ FGTS: Fundo de Garantia do Tempo de Serviço, consiste em uma reserva de dinheiro criada para cada trabalhador.

${ }^{24}$ INSS: Instituto Nacional do Seguro social responsável pelo pagamento de benefícios previdenciários.
} 
públicas ou privadas que coletam ou utilizam dados pessoais é feita pela Autoridade Nacional de Proteção de Dados ${ }^{25}$.

\title{
LGPD e o MCI na proteção da privacidade
}

O Marco Civil da Internet é o dispositivo legal relativo a proteção da privacidade no ambiente digital. Ela disciplina princípios, garantias, direitos e deveres dos usuários. Em seu art. $3^{\circ}$, incisos II e III, determina que a proteção da privacidade e dos dados pessoais são princípios que devem ser seguidos no uso da internet no Brasil. E a LGPD também é uma lei que busca assegurar a privacidade dos usuários em meio as novas tecnologias, em que para tanto, regulamenta como irá ocorrer o tratamento de dados dos usuários pelas empresas.

Nesse sentido, faz-se indispensável estabelecer distinções entre tais leis que possuem objetivos semelhantes. Dessa maneira, as diferenças entre elas residem no ato de que o MCI deixou lacunas, em que a principal delas refere-se a sua fragilidade de efetivação perante o plano internacional (STRASSER, 2020). Isso porque, tal lei:

\begin{abstract}
Determina a aplicação da lei nacional nos casos em que as consequências dos atos ilícitos de uma relação jurídica internacional se dão em território brasileiro (lex damni) e nos casos em que umas das partes envolvidas seja domiciliada no Brasil (lex domicilii) (PINHEIRO, apud STRASSER).
\end{abstract}

Diante disso, percebe-se que se os responsáveis pelo tratamento de dados forem estrangeiros a aplicação do MCI se torna limitada. Enquanto a LGPD possui capítulo próprio para tratar da transferência internacional de dados, em que determina que essa transferência se dará apenas com países que demonstrarem elevado grau de proteção de dados, dentre outros dispositivos que visam assegurar a proteção de dados perante outros países.

Outra diferença verifica-se quanto a falta de previsão legal pela MCI de como se daria utilização pelas empresas, dos dados fornecidos pelos usuários. Diante disso, a LGPD se preocupou em discorrer sobre tanto, protegendo os dados pessoais de modo geral, não apenas aqueles referentes ao mundo online. Logo, abrange também o amparo aos dados resultantes do ambiente off-line.

Portanto, a LGPD resguardar os direitos fundamentais no ambiente tecnológico na sua totalidade. E o MCI, por ser anterior, não dispôs sobre todos os temas necessários para tanto, uma vez que a sociedade hodierna está evoluindo informaticamente com uma velocidade surpreendente. No entanto, não representa exclusão ao MCI, pois uma é complementar a outra. Assim, ambas contribuem para a proteção do livre desenvolvimento da personalidade da pessoa natural, tal como seus direitos fundamentais de privacidade e liberdade, nos termos da LGPD em seu art.I7.

\section{DIREITO À PRIVACIDADE E A INTIMIDADE NA INTERNET}

Todo ser, pela Constituição Federal de 1988, possui direitos e deveres. Isso é algo

\footnotetext{
${ }^{25}$ ANPD: A Autoridade Nacional de Proteção de Dados, consiste no órgão da administração pública direta federal do Brasil que integra na Presidência da República, como também atribui nas relações da Lei Geral Proteção de Dados, contribui realizar a fiscalização do cumprimento da Lei nº 13.709/2018.
} 
inquestionável, entretanto, com a "Era Cibernética", percebe-se que o direito à privacidade e à intimidade são um dos mais violados na internet. Dessa forma, o que seria direito à privacidade e à intimidade na internet? Faz-se necessário conhecer osdireitos supracitados, esses que são postulados pela Constituição Federal, queestabelece:

\begin{abstract}
Art. $5^{\circ}$. Todos são iguais perante a lei, sem distinção de qualquer natureza, garantindo-se aos brasileiros $e$ aos estrangeiros residentes no País a inviolabilidade do direito à vida, à liberdade, à igualdade, à segurança e à propriedade, nos termos seguintes: (...) X - são invioláveis a intimidade, a vida privada, a honra e a imagem das pessoas, assegurado o direito a indenização pelo dano material ou moral decorrente de sua violação.
\end{abstract}

Diante disso, é de suma importância destacar o que é intimidade e privacidade. Nesse diapasão, de acordo com o entendimento de René Ariel Dotti, em seu "Proteção da Vida Privada e Liberdade de Informação: possibilidades e limites", a intimidade corresponde à "esfera secreta da vida do individuo na qual este tem o poder legal de evitar os demais" (DOTTI, 1980 apud BENTIVEGNA, 2020, p. 152). Em contrapartida, para Bernardo Gonçalves “o direito à privacidade está ligado à exigência de o indivíduo encontrar-se protegido na sua solidão, na sua paz e tranquilidade, sendo a reclusão periódica uma necessidade da vida moderna, até mesmo como elemento de saúde mental", (2020, p. 575). Dessa maneira, observa- se que há uma grande semelhança na definição do que seria intimidade e privacidade, para muitos doutrinadores essas duas palavra são sinônimos, noentanto, é importante destacar que para Paulo José da Costa Jr:

A esfera privada compreende todos aqueles comportamentos e acontecimentos que o indivíduo não quer que se tornem de domínio público.E a respeito da esfera da intimidade, leciona: "Fazem parte desse campo conversações ou acontecimentos íntimos, dele estando excluídos não só os quivis ex-populo, como muitos membros que chegam a integrar a esfera pessoal do titular do direito à intimidade". Vale dizer, da esfera da intimidade resta excluído não apenas o público em geral, como é óbvio, bem assim determinadas pessoas, que privam com o indivíduo num âmbito mais amplo. (COSTA, 2007, BLUM, 2018, p. 26)

É de suma importância frisar que o conceito de privacidade muda em decorrência do tempo para se adequar a sociedade da época. Dessa forma, sua compreensão no período histórico de seu surgimento diverge do conceito hodierno. Nesse sentido, o entendimento do que era privacidade em seus primórdios retorna a Roma Antiga, consoante Fernandes (1996), em que estava relacionada a ideia de amparo a vida privada dos indivíduos, desde que dentro de suas propriedades. Assim, seu resguardo era muito limitado e não possuía patamar de direito fundamental, ademais, pertencia apenas aqueles indivíduos que se encontravam emuma propriedade.

No entanto, somente no século XIX (SILVEIRA, 1997, p.13), diante da ascensão burguesa que a privacidade começou a ser tratada como um direito, possuindo valor para integrar os direitos básicos dos indivíduos. Isso ocorreu mediante a obra "A Treatise of The Law of Torts" de Cooley, de 1880 , em que o supramencionado direito passou a ser entendido como "the right to be alone", o que pode ser objetivamente interpretado como o direito de permanecer só, ou seja, é compreendido como um dever de abstenção. Além disso, tal direito também ganhou força mediante o artigo publicado em i89o, de Warren e Brandeis"The Right to Privacy", em que defenderam que as inovações tecnológicas demandariam a proteção dos bens jurídicos que estas poderiam ameaçar (I89o, p.197 - 213). 
Indubitavelmente, ideia de direito a privacidade continua evoluindo, na medidaem que a sociedade avança. Com isso, é notório que o advento da internet provocou um impacto em todas as esferas sociais o que demanda da evolução da compreensão do direito a privacidade para abarcar as novas situações que são provocadas por tal fenômeno. Diante disso, Rodotá (2008, p.15) expõe adequada compreensão do direito a privacidade na sociedade hodierna, qual seja: "o direito de controlar a maneira na qual os outros utilizam as informações a nosso respeito" ou "direito de manter o controle sobre suas próprias informações e de determinar a maneira de construir sua própria esfera particular”. Entretanto, em frente a

"Sociedade Informacional" o que se tem percebido é incapacidade do Direito de preservar plenamente a privacidade dos indivíduos. Desse modo, convém explanar como ocorre a violação de tal direito fundamental no meio digital:

Uma característica natural de ambientes IoT é a prevalência de dispositivos,
sensores, leitores e aplicativos que têm o potencial de coletar uma multiplicidade
de tipos de dados de indivíduos à medida que os mesmos se movem nesses
ambientes. As possibilidades de identificar objetos automaticamente podem levar
a uma identificação automática de pessoas relacionadas a esses objetos. As
informações coletadas com base em identificadores de dispositivos, dados de
sensores e capacidades de conexão de sistemas IoT podem, portanto, revelar
informações sobre indivíduos, seus hábitos, localização, interesses e outras
informações pessoais e outras preferências armazenadas localmente ou em
nuvem. Em combinação com dados disponíveis em outros serviços ou fontes de
informação, as atividades de mineração de dados podem até criar novos
conhecimentos sobre indivíduos que podem não ser revelados examinando
separadamente os conjuntos de dados subjacentes, ferindo a privacidade dos
usuários de maneira colateral. (CAMARGO e SANTOS, 202o, p. i23)

A partir de toda essa discussão, um ponto crucial nessa conjuntura foi a promulgação da Lei 12.737 , 2012 ${ }^{27}$, mais conhecida como Lei Carolina Dieckmann, que alterou o Código Penal Brasileiro no que tange a crimes e delitos informáticos, onde essa lei recebeu esse nome devido ao caso ocorrido com a atriz Carolina Dieckmann em maio de 2011 no qual um hacker (criminoso virtual) invadiu o computador pessoal da atriz, possibilitando que tivesse acesso a 36 fotos pessoais de cunho íntimo. Nesse sentido, percebe-se que tal caso foi o pontapé para que iniciasse a discussão e posteriormente houvesse mudanças no ordenamento jurídico.

Entretanto, HOFFMANN-RIEM (2021, p.74) afirma que a ideia tradicional de privacidade está desgastada e necessita de uma proteção especifica. Nesse diapasão, o Direito buscou assegurar essa proteção por meio da LGPD e do Marco Civil da Internet, assim o direito a privacidade passa a tutelar também os dados dos indivíduos no ambiente digital. Contudo, mesmo com a relevância dessas leis, percebe-se que é irrisória mediante a complexidade do assunto, necessitando ainda de uma melhor estruturação para que cada vez aconteça em menor escala situações semelhantes ao caso disposto anteriormente.

\footnotetext{
${ }^{26}$ Internet das coisas, significa a conexão da internet a objetos físicos.

${ }^{27}$ Para mais informações sobre a lei: https://fmp.edu.br/lei-carolina-dieckman-voce-sabe-o-que-essa-leirepresenta/
} 


\section{INSTAGRAM E A VIOLAÇÃO DA PRIVACIDADE DE SEUS MEMBROS}

Grande parte das redes sociais faz uso de certos "métodos" para tornar esses ambientes virtuais mais agradáveis aos seus usuários e, por consequência, aumentar o tempo em que estes as utilizam. Essa prática, porém, além de colocar em risco o direito à privacidade, também denota o quão poderosas essas redes são, haja vista toda a gama de informações em posse delas.

Entre esses métodos, têm-se os algoritmos ${ }^{28}$, que são artifícios capazes de esquematizar o perfil individual de cada utente e constatar quais são suas preferências e interesses pessoais, seja por meio de suas pesquisas, publicações ou, até mesmo, interações com outros usuários.

Assim, com essas informações em mãos, torna-se simples proporcionar o marketing para as empresas que patrocinam tais redes sociais e, ainda, "direcionar produtos para um grupo de pessoas preterido aumentando a lucratividade". (HIRSCH; SILVA, 202I, p. II2). Sob essa ótica, pertinente é a visão de Hirsch e Silva sobre o tema:

Redes sociais como o Facebook, Twitter, Instagram e o novo Tik Tok utilizam recursos algorítmicos que visam filtrar as informações e os conteúdos que chegam até seus usuários, personalizando-os a fim de que esteja mais próximo dos gostos e preferências dos usuários, ou melhor dizendo, próximo do que eles acham que é melhor para estes usuários. (2021, p. II2).

Tendo em vista o descrito, a seguir, será analisado determinado acontecimento que envolve o Instagram e serve como amostra exemplificativa do risco que as redes sociais trazem aos seus usuários.

Criado pelo empreendedor estadunidense Kevin Systrom e, também, pelo empresário brasileiro Mike Krieger, o Instagram se destaca como uma das redes sociais mais populares do mundo ${ }^{29}$. A princípio, essa plataforma - que permite a produção, edição e reprodução tanto de fotos quanto de vídeos - seria destinada exclusivamente a celulares com o sistema operacional iOS, contudo, após fazer bastante sucesso com os usuários da App Store, os desenvolvedores desse aplicativo decidiram disponibilizá-lo, também, aos aparelhos Android.

Esse fato desencadeou o número recorde de I milhão de downloads em somente 24 horas, tornando-o um dos poucos aplicativos a atingir tal feito (ARAGÃO, 2013, p. 8).Por essa razão, em meados de Abril de 2012, o Facebook comprou a empresa Instagram pela considerável quantia de I bilhão de dólares ${ }^{30}$.

O principal diferencial do Instagram em relação às outras redes sociais reside no fato desse serviço oferecer uma maior experiência visual, com pouca presença de

\footnotetext{
${ }^{28}$ Complexo de fórmulas e dados matemáticos utilizados tanto pelas redes sociais quanto por buscadores online a fim de definir quais resultados ou conteúdos estarão em evidência para os seus usuários.

${ }^{29} \mathrm{O}$ Instagram ficou em quarto lugar no ranking de aplicativos mais baixados entre 2010 e 2019. (BBC NEWS, 2019. Disponível em: 〈https://www.bbc.com/news/technology-50838013〉.).

30 "O Facebook comprou a start-up de compartilhamento de fotos por US \$ I bilhão em 2012, pagando o que parecia uma quantia chocante de US \$ I bilhão para uma empresa com I3 funcionários na época." (CNBC, 2019, tradução nossa. Disponivel em:

〈https://www.cnbc.com/2019/o9/24/facebook-bought-instagram-because-it-was-scared-of-twitter-andgoogle.html>.).
} 
elementos textuais, sem que isso ponha em risco a possibilidade de interação entre os seus usuários. A propósito, grande parte da interação que ocorre no Instagram decorre da troca de curtidas e comentários realizados pelos seguidores nas mídias publicadas nas contas dos usuários, os quais podem, inclusive, decidir se irão ounão deixar essas contas abertas ao público. Além disso, há a oferta de um espaço destinado a troca de mensagens diretas e privadas, fazendo com que ele reúna, em um só aplicativo, diversas funções particulares de outros softwares.

Entretanto, embora seja um espaço destinado ao convívio social entre aqueles que o utilizam, o Instagram, assim como as outras redes sociais, pode ser mal utilizado e, por consequência, servir como um instrumento de violação ao direito à privacidade.

A exemplo disso, convém citar Da Rosa:

Devido a uma funcionalidade similar ao Snapchat, em que uma foto enviada se apaga automaticamente em alguns segundos, as vítimas enviamfotos ou vídeos de cunho íntimo para pessoas que acreditavam ser de confiança, que podem ser salvas, de má-fé por quem os recebe [...] com o intuito de divulgar sem permissão. (2018, p. 35).

Diante disso, é de suma importância mencionar que no dia 20 de outubro de 2020 , o Procon-SP notificou o FACEBOOK SERVIÇOS ONLINE DO BRASIL LTDA - atual proprietário do Instagram, WhatsApp, Snapchat e outros - a respeito do vazamento de dados de usuários da rede social: Instagram ${ }^{31}$. Em vista disso, de acordo com o jornal britânico Telegraph, o Instagram teria exposto informações de perfis de aproximadamente 5 milhões de usuários menores de idade ${ }^{32}$, ou seja, a rede social em questão violou o direito a privacidade e a intimidade de quase 5 milhões de pessoas, essas que por sinal possuem uma maior vulnerabilidade se comparada com o público adulto, visto que "em tese" não possuem o discernimento que uma pessoa adulta tem $^{33}$.

Nesse sentido, o Procon de São Paulo ao notificar o proprietário de tal rede, o questionou de maneira clara acerca de algumas questões importantes que estão ligadas diretamente a privacidade do usuário. À vista disso, foi questionado se é feita a comunicação de forma ostensiva aos usuários da plataforma de que seus dados serão coletados ao ingressarem na sua rede, quais serão os dados coletados e se são solicitados de forma com que haja o consentimento dos que utilizam a ferramenta, se os usuários são

\footnotetext{
${ }^{31}$ "Procon-SP notifica Facebook: Empresa deverá esclarecer ocorrência de vazamento de dados dos usuários". https://www.procon.sp.gov.br/procon-sp-notifica-facebook/

${ }^{32}$ "Procon-SP notifica Instagram por vazar dados de menores de idade". https://olhardigital.com.br/2020/10/21/noticias/procon-sp-notifica-instagram-porvazar-dados-de-menoresde-idade/

${ }^{33}$ Direito entende que os indivíduos menores de 18 anos não possuem capacidade de discernimento apurada, em vista da sua pouca experiência com a sociedade. Esse tempo também é reservado para seu aprendizado, com a finalidade de melhor realizar suas futuras escolhas importantes. Assim, o Direito Civil, entende que a personalidade civil começa a partir do nascimento ( $\mathrm{CC}$, art. $2^{\circ}$ ), no entanto, até os 16 anos são absolutamente incapazes (CC, art. $3^{\circ}$ ) e aqueles maiores de 16 aos 18 anos são relativamente incapazes (CC, art. $4^{\circ}, \mathrm{I}$ ). Ademais, mesmo entendimento é adotado pelo Direito Penal, uma vez que os menores de 18 anos são inimputáveis (CP, art.27).

https://domtotal.com/noticia/1288011/2018/o8/menores-capacidades-e-

direitos/\#: :text=O\%20C\%C3\%B3digo\%20Civil\%2oindica\%2oque,para\%2oatuar\%2ona\%2ovida\%20civil.\&tex $\mathrm{t}=$ Falta\%20a\%2oessas\%2opessoas\%20capacidade,atos\%2odentro\%20do\%2oDireito\%2oCivil.
} 
informados sobre o tratamento que será aplicado aos seus dados, tais como coleta, compartilhamento, armazenamento ou finalidades empresariais entre outras. Além disso, foi questionado se, realmente, o Instagram está realizando, de maneira adequada, o que é postulado pela Lei Geral de Proteção de Dados (Lei no 13.709/2018).

Fica claro, portanto, que na maioria das vezes os usuários de tais ferramentas não detêm do saber que ao ingressarem com seus e-mails e dados pessoais em determinadas plataformas digitais estão sendo alvos de uma exacerbada venda de informações a respeito dos seus gostos e afins, essas que possuem vínculos lucrativos para as empresas que patrocinam a ferramenta utilizada pelo usuário, pois é por meio dessas informações "vendidas" que será possível bombardear o feed ${ }^{34}$ da pessoa com produtos que talvez possua interesse em comprar. Nessa perspectiva, é evidente que o direito a privacidade está sendo violado, pois as informações de cunho íntimo do usuário são repassadas as empresas patrocinadoras, essas que irão mostrar propagandas voltadas ao que é de interesse do indivíduo, a fim de fazer com que o mesmo compre algo que havia comentado com um outro usuário da plataforma por meio da ferramenta de conversa que disponibiliza.

\section{CONCLUSÃO}

O presente trabalho buscou observar a necessidade de refletir acerca da privacidade na internet e os impactos que ela pode causar. Além disso, é necessário que os antigos conceitos precisem ser avaliados, contendo novas perspectivas, visto que o ser humano ampliou suas fronteiras, do modo que se vive, atualmente, no espaço virtual, por exemplo. Nesta conjuntura, a privacidade ganha novos contornos, tendo em vista a grande evolução tecnológica. Diante disso, a formação de um regime de proteção de dados bem regulado, junto a todas as consequências que inevitavelmente implica alcançar pontos bastante diversos. Tendo que existir, obrigatoriamente, um esforço legislativo, que resulte em uma eficiente norma que dê conta de todas as contingências tecnológicas do debate que se trava.

Em síntese, a Lei Geral de Proteção de Dados Pessoais (LGPD), Lei no 13.709/2018, é a legislação brasileira que regula as atividades de tratamento de dados pessoais. Nesse viés, buscou-se analisar como a criação da LGPD foi importante para a sociedade, e como ela ajudou na privacidade e na segurança de dados pessoais. A presente pesquisa tratou-se sobre a proteção da privacidade na LGPD (como se aplica), os impactos que causou nas empresas e suas transformações, além de como a LGPD e o MCI abordam em suas respectivas codificações acerca da proteção da privacidade e intimidade, e o quanto foi importante tal avanço. Ademais, explicou-se sobre o direito a privacidade e a intimidade na internet e, por último e não menos importante, foi discutido acerca do Instagram e a violação da privacidade de seus membros, de modo que ainda precisa ser analisado o uso de dados de usuários de maneira ilícita.

Dessa forma, ficou evidente a importância do estudo aprofundado referente aos aspectos jurídicos da exposição de dados pessoais na internet e a sua relação com o direito

\footnotetext{
34 Feed se origina da palavra inglesa "alimentar". Desse modo, os usuários não precisam ir atrás de informações atualizadas nos sites, pois este já desempenha esse trabalho. Assim, os vídeos, fotos ou notícias que aparecem para os usuários seguem o padrão de postagens que ele mais visualiza ou procura. No Instagram se caracteriza pelo fluxo de conteúdo que permite rolagem e dispostos em blocos com apresentações semelhantes com conteúdos atualizados do que o usuário costuma mais procurar na rede.
} 
fundamental à privacidade. Sendo assim, o estudo mostrou o quanto esse assunto ainda precisa ser difundido e o quanto é relevante para o ramo do direito.

\section{REFERÊNCIAS}

ARAGÃO, R. Usos jornalísticos do Instagram: aproximações a partir do JC Imagens. In: Congresso de Ciências da Comunicação na Região Nordeste, XIV, 2013, Mossoró. Comunicação em tempo de redes sociais: afetos, emoções, subjetividades. São Paulo: Intercom, 2013. Disponível em: https://portalintercom.org.br/anais/nordeste2013/resumos/R37-0922-I.pdf . Acesso em: II de setembro de 2021.

BARROS, B. M. C.; PEREIRA, M. N.; OLIVEIRA, R. S. O direito à privacidade na internet: Desafios para a proteção da vida privada e o direito ao esquecimento. Revista da Faculdade de Direito da Universidade Federal de Minas Gerais, Belo Horizonte, v.7o, n. 70, p. 56I - 594, 2017.

BASTOS, E. A. V.; PANTOJA, T. I. S.; SANTOS, S. H. C. S. Os impactos das novas tecnologias da informação e comunicação no direito fundamental á privacidade. Brazilian Journal of Development, Curitiba, v.7, n.3, p. 29247-29267, 2021.

BBC. Facebook owns the four most downloaded apps of the decade. Disponivel em: https://www.bbc.com/news/technology-50838013. Acesso em: II de setembro de 202I

BENTIVEGNA, Carlos Frederico Barbosa. Liberdade de expressão, honra, imagem e privacidade: os limites entre o lícito e o ilícito. I. ed. São Paulo: Manole, 2020.

BRASIL, Lei no 13.709, de 14 de agosto de 2018. Lei Geral de Proteção de Dados Pessoais (LGPD). Disponível em: <http://www.planalto.gov.br/ccivil_03/_ato20152018/2018/lei/li3709.htm>. Acesso em: 03 de setembro de 2021.

BLUM, Rita Peixoto Ferreira. O Direito à Privacidade e à Proteção dos Dados do Consumidor. I. ed. São Paulo: Almedina, 2018.

CNBC. As calls grow to split up Facebook, employees who were there for the Instagram acquisition explain why the deal happened. Disponível em: https://www.cnbc.com/2019/o9/24/facebook-bought-instagram-because-it-was-scared-oftwitter-and-google.html. Acesso em: in de setembro de 2021.

COMO SURGIU A LEI GERAL DE PROTEÇÃO DE DADOS. ACERVO, 202I. Disponível em: https://acervonet.com.br/blog/como-surgiu-a-lei-geral-de-protecao-dedados-lgpd/

Constituição (1988). Constituição da República Federativa do Brasil. Disponível em: http://www.planalto.gov.br/ccivil_03/constituicao/ConstituicaoCompilado.htm. Acesso ago. 202I 
Costa-Corrêa, A.; Predolim, E. A.; Longhi, M.I.C. S.; Ferna, R. Direito e Novas Tecnologias. Almedina: Grupo Almedina (Portugal), 2020.

DA ROSA, Gabriela Schmoeller. Análise do direito à privacidade das publicações nas redes sociais digitais. 2018. Trabalho de Conclusão de Curso (Graduação em Direito) Curso de Direito, Universidade do Sul de Santa Cantarina, Santa Catarina, 2018.

DONEDA, D. A proteção dos dados pessoais como um direito fundamental. Espaço Jurídico Journal off Law, vol. I2, n. 2, p. 9I-Io8, 20Ir. Disponível em: https://dialnet.unirioja.es/descarga/articulo/4555153. Acesso em: 20 set. 2021.

FERNANDES, Bernardo Gonçalves. Curso de Direito Constitucional. I2. ed. Salvador: JusPodivm, 2020.

FRANCA, R. P; FARIAS, R. V. A Tutela Material e Processual da Privacidade no Meio Ambiente Digital. EMERJ, Rio de Janeiro, v. 20, n. 2, p. 29I-3II, 2018.

FUGAZZA, G. Q.; SALDANHA, G. S. Privacidade, ética e informação: uma reflexão filosófica sobre os dilemas no contexto das redes sociais. Encontros Bibli, v. 22, n. 50, p. 91IOI, 2017.

Garcia, Lara R. Lei Geral de Proteção de Dados (LGPD): Guia de implantação. Editora Blucher, 2020.

HIRSCH, Carla Conchita; SILVA, Larissa Amaral (org). Estudos universitários de direitos fundamentais. Salvador: Direito Levado a Sério, 2021.

HOFFMANN-RIEM, Wolfgang. Teoria geral do direito digital: transformação digital: desafios para o direito. Rio de Janeiro: Forense, 2021.

Jornal The Guardian disponível. Março, 2018. Disponível em $<$ https://canaltech.com.br/redes-sociais/campanha-de-trump-usou-dados-de-5o-milhoesde-usuarios-do-facebook-ıior56/> Acesso em out. 2021.

LIMA, L. A. Diretrizes para aperfeiçoamento e interpretação da lei do marco civil da internet com vistas à garantia do direito à privacidade nas redes sociais. Prisma Jurídico, São Paulo, v.17, n. I, p.59-8I, 2018.

MORAES, M. C. B.; TEFFÉ, C. S. Redes sociais virtuais: privacidade e responsabilidade civil Análise a partir do Marco Civil da Internet. Pensar. Revista de Ciências Jurídicas, Fortaleza, v. 22, n. I, p. 108-146, 2017.

Quintiliano, Leonardo. Contexto histórico e finalidade da Lei Geral de Proteção de Dados (LGPD). IAPD, I9 de março de 2021. Disponível em: https://iapd.org.br/contextohistorico-e-finalidade-da-lei-geral-de-protecao-de-dados-lgpd/. Acesso em: 03 de setembro de 202I 
Revista: Consultor Jurídico, 24 de setembro de 2020. Disponível em < https://www.conjur.com.br/2020-set-24/pratica-trabalhista-adequacao-lgpd-recrutamentoselecao-candidatos-emprego $>$ Acesso em out. 2021.

RODOTÁ, Stefano. A Vida nas Sociedades da Vigilância: A Privacidade hoje. Org. Maria Celina Bodin de Moraes. Trad. Danilo Doneda e Luciana Cabral Doneda. Rio de Janeiro, São Paulo e Recife, Renovar: 2008.

SANÇÕES ADMINISTRATIVAS: O QUE MUDA APÓS I DE AGOSTO DE 202ז. CRYPTOID. 202I. Disponível em: <https://cryptoid.com.br.> Acesso em: set. 2021

SANTOS, C. O. Lei Geral de Proteção de Dados (LGPD), Lei n 13.709/2018: direito á privacidade aplicado às redes sociais. Repositorio Pucgoias, Goiânia. (p.6-34), jun, 202I.

STRASSER, F. A. C.; OLIVEIRA, M. G. O advento da internet e seus desafios no campo jurídico brasileiro: breve análise dos dispositivos sobre o mundo. Colloquium Socialis, Presidente Prudente, v. 03, n. 4, p.6-19 out/dez2org.

UNIÃO EUROPEIA. Parlamento Europeu. Diretiva 95/46/CE. Disponível em https://eur-lex.europa.eu/legal-content/PT/ALL/?uri=celex\%3A31995Loo46 . Acesso em: Set. de 202I.

WARREN, Samuel D.; BRANDEIS, Louis D. The right to privacy. Harvard Law Review, v. 4, n. 5, p. 193-220, dez. 1890. 